\title{
Carboplatin plus nanoparticle albumin-bound paclitaxel for the treatment of thymic carcinoma
}

\author{
AKIKO TAKAHASHI, RINTARO NORO, NATSUKI TAKANO, KAKERU HISAKANE, SATOSHI TAKAHASHI, \\ AYA FUKUIZUMI, MIWAKO OMORI, TEPPEI SUGANO, SUSUMU TAKEUCHI, SHINJI NAKAMICHI, \\ AKIHIKO MIYANAGA, YUJI MINEGISHI, KAORU KUBOTA, MASAHIRO SEIKE and AKIHIKO GEMMA
}

Division of Pulmonary Medicine and Oncology, Graduate School of Medicine, Nippon Medical School, Tokyo 113-8603, Japan

Received October 31, 2021; Accepted January 25, 2022

DOI: $10.3892 / \mathrm{mco} .2022 .2520$

\begin{abstract}
Thymic carcinoma is a relatively rare type of malignant tumor. The present retrospective study evaluated the efficacy and safety of carboplatin plus nanoparticle albumin-bound paclitaxel for the treatment of advanced thymic carcinoma. The study included data from 12 patients with advanced thymic carcinoma treated in the Nippon Medical School Hospital (Tokyo, Japan). Response to treatment, patient survival and treatment safety were assessed. The objective response rate was $66.7 \%$ (8/12 patients). Disease control was achieved in 11 patients $(91.7 \%)$. At the median follow-up time of 27.6 months (range, 6.2-75.1 months), the median progression-free survival and median first-line overall survival times were 16.7 months [95\% confidence interval (CI), 13.2-37.7] and 14.3 months (95\% CI, 4.7-54.6), respectively. There was no occurrence of febrile neutropenia or treatment-related death. The results of the present study showed that carboplatin plus nanoparticle albumin-bound paclitaxel was effective and safe. Therefore, it is a promising chemotherapy regimen for the treatment of advanced thymic carcinoma.
\end{abstract}

\section{Introduction}

Although thymoma and thymic carcinoma are relatively rare types of malignant tumors, they account for most mediastinal tumors in adults globally (1-3). Thymomas are a common primary tumor in the anterior mediastinum, although they are rare (1.5 cases/million). Thymic carcinoma is rarer than thymomas. In 2016, the National Comprehensive Cancer Network Guidelines version 2 (4) recommended six combination chemotherapy regimens, excluding radiotherapy, for patients with unresectable disease (5-7). According to the guidelines, carboplatin plus

Correspondence to: Dr Rintaro Noro, Division of Pulmonary Medicine and Oncology, Graduate School of Medicine, Nippon Medical School, 1-1-5, Sendagi, Bunkyo-ku, Tokyo 113-8603, Japan E-mail: r-noro@nms.ac.jp

Key words: thymic carcinoma, chemotherapy, nanoparticle albumin-bound paclitaxel paclitaxel is the recommended regimen for the treatment of patients with thymic carcinoma, owing to the higher response rate compared with that noted for other regimens. However, there is a lack of data from randomized clinical studies to provide a definite indication for the management of this disease.

Nanoparticle (i.e., $130 \mathrm{~nm}$ ) albumin-bound paclitaxel (nab-paclitaxel) utilizes the properties of albumin, namely the reversible binding of paclitaxel, the subsequent transportation across the endothelial cells and its concentration in the tumor. Since it does not contain solvents or ethanol, paclitaxel can be administered at higher doses than those recommended without premedication (8). Nab-paclitaxel is used without dissolving alcohol and so would be available for treating patients who were allergic to alcohol. In addition, the safety and efficacy of nab-paclitaxel have been demonstrated in patients with various types of cancer at a range of doses $\left(100-260 \mathrm{mg} / \mathrm{m}^{2}\right)(9-13)$. The present retrospective study evaluated the efficacy and safety of carboplatin plus nab-paclitaxel for the treatment of advanced thymic carcinoma.

\section{Materials and methods}

Patients. The present study was conducted on retrospective data from patients treated between December 2013 and November 2017. The last day for survival confirmation was August 30,2019. During this period, 12 patients with advanced thymic carcinoma received treatment with carboplatin plus nab-paclitaxel at the Nippon Medical School Hospital (Tokyo, Japan). All patients were treated with carboplatin on day 1 [area under the blood concentration time curve (AUC), 6] plus nab-paclitaxel $\left(100 \mathrm{mg} / \mathrm{m}^{2}\right)$ on days 1,8 and 15 in cycles repeated every 3 weeks. The medical records of the patients were retrospectively reviewed. The inclusion criteria were as follows: i) Confirmed diagnosis of thymic carcinoma according to the histopathological criteria proposed by the World Health Organization (2014 version) (14); ii) stage III (a thoracic surgeon had rejected these patients as the tumors had infiltrated major vessels.), IVa or IVb disease according to the Masaoka criteria (15); and iii) recurrence or metastases diagnosed through chest or abdominal computed tomography. There were no exclusion criteria. The protocol of this study was approved by the Institutional Review Board of the Nippon Medical School Hospital (approval no. 30-05-933). 
Evaluation of response to treatment and safety. The Response Evaluation Criteria in Solid Tumors (version 1.1) guidelines (16) were used to evaluate tumor responses, including complete response (CR), partial response (PR), stable disease (SD) and progressive disease (PD). Disease control rate (DCR) was defined as the sum of CR, PR and SD values.

Progression-free survival (PFS) time was defined as the period from the first day of administration of carboplatin plus nab-paclitaxel to the day of documented disease progression or death. Overall survival time was defined as the period from the first day of administration of carboplatin plus nab-paclitaxel to the day of death; patients who remained alive were censored on the date of the last visit. Follow-up time was defined as the median time between the first day of treatment and the day of death or last follow-up visit. Survival curves were plotted using the Kaplan-Meier method.

Safety was assessed according to the Common Terminology Criteria for Adverse Events (version 4.0; nih.gov) (17) of the US National Cancer Institute.

Statistical analysis. Survival curves were plotted using the Kaplan-Meier method and analyzed by the log-rank test. Analyses were performed using GraphPad Prism version 8 (GraphPad Software, Inc.). $\mathrm{P}<0.05$ was used to indicate a statistically significant difference.

\section{Results}

Patient characteristics. A total of 12 patients were included in the present study (Tables I and SI). Among those patients, 2 underwent a tumor resection. Squamous cell carcinoma was the most common histological type (75.0\%). All patients had a performance status of $0-1$, and were treated with carboplatin on day 1 (area under the blood concentration time curve, 5-6) plus nab-paclitaxel $\left(100 \mathrm{mg} / \mathrm{m}^{2}\right)$ on days 1,8 and 15 in cycles repeated every 3-4 weeks.

Four patients had received prior chemotherapy: Three patients had received paclitaxel $\left(200 \mathrm{mg} / \mathrm{m}^{2}\right)$ plus carboplatin (AUC, 6) 12 months ago, and one patient had received paclitaxel $\left(200 \mathrm{mg} / \mathrm{m}^{2}\right)$ plus carboplatin (AUC, 6) 7 months ago, irinotecan $\left(100 \mathrm{mg} / \mathrm{m}^{2}\right)$ plus cisplatin $\left(30 \mathrm{mg} / \mathrm{m}^{2}\right)$ (weekly) 6 months ago and docetaxel $\left(60 \mathrm{mg} / \mathrm{m}^{2}\right) 6$ months ago.

Response and survival analysis. The median number of treatment cycles was 4 (range, 2-6). The relative dose intensity was $66.7 \%$. Reasons for the reduction of the dose included alcoholic liver injury and nephropathy. Notably, 3 patients received maintenance treatment with nab-paclitaxel.

Treatment response data are shown in Table II. CR, PR and DCR were achieved in 1 patient $(8.3 \%), 7$ patients $(58.3 \%)$ and 11 patients $(91.7 \%)$, respectively. At the median follow-up time of 27.6 months (range, 6.2-75.1 months), the median PFS time of 12 patients was 16.7 months [95\% confidence interval (CI), 13.2-37.7] and the median first-line PFS time of 8 patients was 13.6 months (95\% CI, 4.3-42.3) (Fig. 1). The median first-line overall survival time was 14.3 months (95\% CI, 4.7-54.6). Three patients remained disease-free for $>3$ years.

Evaluation of safety. Safety was assessed in all patients. Grade $\geq 3$ hematological adverse events were observed in 7 patients
Table I. Clinicopathological characteristics $(n=12)$.

\begin{tabular}{lc}
\hline Characteristic & Value \\
\hline Sex, n (\%) & \\
Male & $7(58.3)$ \\
Female & $5(41.7)$ \\
Age, years & \\
Median (range) & $64(41-73)$ \\
Histology & \\
Squamous cell carcinoma & $9(75.0)$ \\
Undifferentiated carcinoma & $2(16.7)$ \\
Neuroendocrine carcinoma & $1(8.3)$ \\
Clinical stage & \\
III & \\
Iva & $2(16.7)$ \\
IVb & $3(25.0)$ \\
Postoperative recurrence & $5(41.7)$ \\
Prior therapy & $2(16.7)$ \\
No & \\
Chemotherapy & $8(66.7)$ \\
Performance status & $4(33.3)$ \\
0 & \\
1 & $6(50.0)$ \\
\hline
\end{tabular}

${ }^{\mathrm{a}}$ Clinical stage was defined based on the Masaoka criteria.

Table II. Response to treatment $(n=12)$.

\begin{tabular}{lc}
\hline Response & $\mathrm{n}(\%)$ \\
\hline Complete response & $1(8.3)$ \\
Partial response & $7(58.3)$ \\
Stable disease & $3(25.0)$ \\
Progressive disease & $1(8.3)$ \\
Disease-control rate & $11(91.7)$ \\
\hline
\end{tabular}

(anemia, $n=3$; decreased platelet count, $n=2$; neutropenia, $\mathrm{n}=2$; and hyponatremia, $\mathrm{n}=1$ ). A grade $\geq 3$ non-hematological adverse event (liver disfunction) was observed in 1 patient. For the 3 patients with prolonged grade 3 anemia, the dosage was reduced to $80 \%$ of the initial dose. Neuropathy, febrile neutropenia and treatment-related mortality did not occur in this study (Table III).

\section{Discussion}

To the best of our knowledge, the present study is the largest investigation conducted thus far to assess the clinical benefits of carboplatin plus nab-paclitaxel in patients with advanced thymic carcinoma. As thymoma and thymic carcinoma are relatively rare types of malignant tumors, this combination may be an option as a chemotherapy regimen for the treatment of advanced thymic carcinoma. 
Table III. Adverse events.

\begin{tabular}{|c|c|c|c|c|}
\hline Adverse event & All grades, $\mathrm{n}$ & $\%$ & Grade $\geq 3, \mathrm{n}$ & $\%$ \\
\hline \multicolumn{5}{|l|}{ Hematological } \\
\hline Leukopenia & 2 & 16.7 & 2 & 16.7 \\
\hline Neutropenia & 2 & 16.7 & 2 & 16.7 \\
\hline Anemia & 5 & 41.7 & 3 & 25.0 \\
\hline Decreased platelet count & 3 & 25.0 & 2 & 16.7 \\
\hline Febrile neutropenia & 0 & 0.0 & 0 & 0.0 \\
\hline Hyponatremia & 1 & 8.3 & 1 & 8.3 \\
\hline \multicolumn{5}{|l|}{ Non-hematological } \\
\hline Infection & 0 & 0.0 & 0 & 0.0 \\
\hline Fever & 0 & 0.0 & 0 & 0.0 \\
\hline Hepatic injury & 1 & 8.3 & 1 & 8.3 \\
\hline Pneumonitis & 1 & 8.3 & 0 & 0.0 \\
\hline Diarrhea & 1 & 8.3 & 0 & 0.0 \\
\hline Neuropathy & 0 & 0.0 & 0 & 0.0 \\
\hline Febrile neutropenia & 0 & 0.0 & 0 & 0.0 \\
\hline Treatment-related mortality & 0 & 0.0 & 0 & 0.0 \\
\hline
\end{tabular}

Table IV. Studies of carboplatin plus nab-paclitaxel as salvage chemotherapy in patients with thymic carcinoma.

\begin{tabular}{|c|c|c|c|c|c|c|}
\hline First author, year & Patient sex & Age, years & Histology & Response & PFS, months & (Refs.) \\
\hline Makimoto et al, 2014 & Male & 40 & $\mathrm{Sq}$ & PR & - & (19) \\
\hline Igawa et al, 2015 & Male & 59 & LCNEC & PR & $<6$ & (20) \\
\hline Zhan et al, 2015 & Female & 63 & $\mathrm{Sq}$ & PR & $<36$ & $(21)$ \\
\hline Shima et al, 2016 & Male & 22 & Lymphoepithelioma-like & PR & - & (22) \\
\hline Funaishi et al, 2017 & Male & 78 & $\mathrm{Sq}$ & PR & 10.3 & (23) \\
\hline
\end{tabular}

LCNEC, large-cell neuroendocrine carcinoma; nab-paclitaxel, nanoparticle albumin-bound paclitaxel; PFS, progression-free survival; PR, partial response; Sq, squamous cell carcinoma.

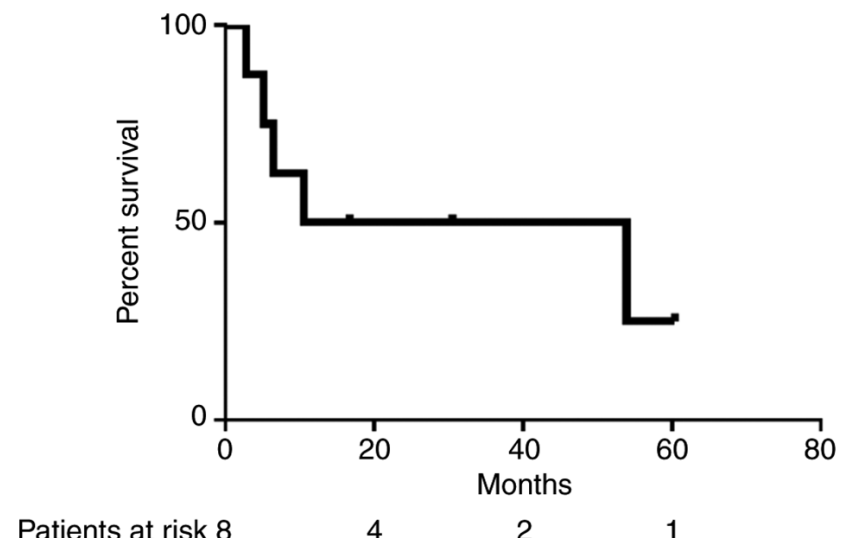

Patients at risk 8

Figure 1. Survival analysis. Progression-free survival for first-line therapy. A total of 3 patients remained disease-free for $>3$ years.

Lemma et al (18) advocated the use of combination chemotherapy consisting of carboplatin plus paclitaxel, in addition to standard therapeutic regimens, for the treatment of advanced thymic carcinoma. Of the 23 patients with thymic carcinoma included in the aforementioned study, 5 patients accomplished a PR, and 12 patients achieved SD (risk ratio, 21.7\%; DCR, 73.9\%). Notably, the PFS time was 5 months. Table IV shows five case reports of patients with thymic carcinoma who received chemotherapy with carboplatin plus nab-paclitaxel (19-22). These case reports showed that the administration of carboplatin plus nab-paclitaxel resulted in favorable antitumor effects against thymic carcinoma. Funaishi et al (23) reported a case with a PFS time of 10.3 months. Ley et al (24) and Maurer et al (25) suggested the clinical benefit of nab-paclitaxel in recurrent/metastatic gynecological and head and neck carcinomas, which are resistant to paclitaxel and docetaxel. These results are consistent with the present findings, indicating that carboplatin plus nab-paclitaxel may be an option for the treatment of advanced thymic carcinoma. Recently, the efficacy and safety of lenvatinib in patients with advanced or metastatic thymic carcinoma was confirmed in a single-arm, phase 2 trial conducted in eight institutions in Japan (five cancer centers, two medical university hospitals and one public 
hospital) (26). In this phase 2 trial, carboplatin and paclitaxel were used as first-line treatment in $71 \%$ of cases. The use of lenvatinib after treatment with carboplatin plus nab-paclitaxel was also an effective alternative.

Gong et al (27) showed that nab-paclitaxel treatment had a high response rate in non-small cell lung cancer (NSCLC) when used as second-line chemotherapy. No significant difference was found between clinical features and the short-term effect of nab-paclitaxel, such as taxanes, or other second-line chemotherapy. It was also determined that nab-paclitaxel may be an appropriate second-line treatment for patients with thymic cancer who had previously received chemotherapy. Additionally, maintenance monotherapy with nab-paclitaxel may be an option to prolong the PFS time of patients with thymic carcinoma. These results are consistent with those obtained after maintenance monotherapy with nab-paclitaxel for NSCLC (28).

In conclusion, the results presented within the present study suggest that carboplatin plus nab-paclitaxel is a promising salvage chemotherapy regimen for the treatment of advanced thymic carcinoma. Thymic cancer is a very rare type of cancer and the present study contained a limited number of patients as the clinical study was conducted in a single facility. Prospective studies are therefore warranted to further evaluate the efficacy of carboplatin plus nab-paclitaxel chemotherapy for the treatment of thymic carcinoma.

\section{Acknowledgements}

Not applicable.

\section{Funding}

No funding was received.

\section{Availability of data and materials}

The datasets used and/or analyzed during the current study are available from the corresponding author on reasonable request.

\section{Authors' contributions}

AT, RN, MS, KK and AG were responsible for the conception and design of the study. Provision of study materials or patients, data collection and analysis, and manuscript writing were completed by AT, RN, NT, KH, ST, AF, MO, TS, ST, SN, AM, YM, KK, MS and AG. AT and RN confirm the authenticity of all the raw data. All authors have read and approved the manuscript.

\section{Ethics approval and consent to participate}

The protocol of this study was approved by the Institutional Review Board of the Nippon Medical School Hospital (Tokyo, Japan; approval no. 30-05-933).

\section{Patient consent for publication}

Not applicable.

\section{Competing interests}

RN received honoraria from AstraZeneca and Chugai Pharmaceutical. ST received honoraria for lectures, presentations and speakers bureaus from Taiho Pharmaceutical. YM received payment or honoraria for lectures and presentations from Boehringer Ingelheim Phamaceuticals and Taiho Pharmaceutical. MS received payment or honoraria for lectures and presentations from Boehringer Ingelheim Phamaceuticals, Taiho Pharmaceutical and Eli Lilly Japan K.K. AG received payment or honoraria for lectures and presentations from Boehringer Ingelheim Phamaceuticals. KK received payment or honoraria for lectures and presentations from Chugai Pharmaceutical, Taiho Pharmaceutical, MSD, Nippon Boehringer Ingelheim, Bristol-Myers Squibb, Kyowa-Hakko Kirin, AstraZeneca and Ono Pharmaceutical.

\section{References}

1. de Jong WK, Blaauwgeers JL, Schaapveld M, Timens W, Klinkenberg TJ and Groen HJ: Thymic epithelial tumours: A population-based study of the incidence, diagnostic procedures and therapy. Eur J Cancer 44: 123-130, 2008.

2. Mariusdottir E, Nikulasson S, Bjornsson J and Gudbjartsson T: Thymic epithelial tumours in iceland: Incidence and histopathology, a population-based study. APMIS 118: 927-933, 2010.

3. Gadalla SM, Rajan A, Pfeiffer R, Kristinsson SY, Bjorkholm M, Landgren $\mathrm{O}$ and Giaccone $\mathrm{G}$ : A population-based assessment of mortality and morbidity patterns among patients with thymoma. Int J Cancer 128: 2688-2694, 2011.

4. National Comprehensive CancerNetwork( $\mathrm{NCCN})$ : Thymomas and Thymic Carcinomas. Version 2.2016. NCCN, Plymouth Meeting, PA, 2016. https://thymicuk.org/wp-content/uploads/2019/10/ NCCN-Thymoma-and-Thymic-cancer-guidelines.pdf. Accessed March 16, 2016.

5. Engels EA: Epidemiology of thymoma and associated malignancies. J Thorac Oncol 5 (10 Suppl 4): S260-S265, 2010.

6. Strollo DC, Rosado de Christenson ML and Jett JR: Primary mediastinal tumors. Part 1: Tumors of the anterior mediastinum. Chest 112: 511-522, 1997.

7. Engels EA and Pfeiffer RM: Malignant thymoma in the United States: Demographic patterns in incidence and associations with subsequent malignancies. Int J Cancer 105: 546-551, 2003.

8. Gradishar WJ: Albumin-bound paclitaxel: A next-generation taxane. Expert Opin Pharmacother 7: 1041-1053, 2006.

9. Gradishar WJ, Tjulandin S, Davidson N, Shaw H, Desai N, Bhar P, Hawkins M and O'Shaughnessy J: Phase III trial of nanoparticle albumin-bound paclitaxel compared with polyethylated castor oil-based paclitaxel in women with breast cancer. J Clin Oncol 23: 7794-7803, 2005.

10. Socinski MA, Bondarenko I, Karaseva NA, Makhson AM, Vynnychenko I, Okamoto I, Hon JK, Hirsh V, Bhar P, Zhang $\mathrm{H}$, et al: Weekly nab-paclitaxel in combination with carboplatin versus solvent-based paclitaxel plus carboplatin as first-line therapy in patients with advanced non-small-cell lung cancer: Final results of a phase III trial. J Clin Oncol 30: 2055-2062, 2012.

11. Hirsh V, Okamoto I, Hon JK, Page RD, Orsini J, Sakai H, Zhang H, Renschler MF and Socinski MA: Patient-reported neuropathy and taxane-associated symptoms in a phase 3 trial of nab-paclitaxel plus carboplatin versus solvent-based paclitaxel plus carboplatin for advanced non-small-cell lung cancer. J Thorac Oncol 9: 83-90, 2014.

12. Koizumi W, Morita S and Sakata Y: A randomized phase III trial of weekly or 3-weekly doses of nab-paclitaxel versus weekly doses of cremophor-based paclitaxel in patients with previously treated advanced gastric cancer (ABSOLUTE trial). Jpn J Clin Oncol 45: 303-306, 2015.

13. Shitara K, Takashima A, Fujitani K, Koeda K, Hara H, Nakayama N, Hironaka S, Nishikawa K, Makari Y, Amagai K, et al: Nab-paclitaxel versus solvent-based paclitaxel in patients with previously treated advanced gastric cancer (ABSOLUTE): An open-label, randomised, non-inferiority, phase 3 trial. Lancet Gastroenterol Hepatol 2: 277-287, 2017. 
14. Travis WD, Brambilla E, Burke AP, Marx A and Nicolson AG: Introduction to The 2015 World health organization classification of tumors of the lung, Pleura, thymus, and heart. J Thorac Oncol 10: 1240-1242, 2015.

15. Masaoka A, Monden Y, Nakahara K and Tanioka T: Follow-up study of thymomas with special reference to their clinical stages. Cancer 48: 2485-2492, 1981.

16. Eisenhauer EA, Therasse P, Bogaerts J, Schwartz LH, Sargent D, Ford R, Dancey J, Arbuck S, Gwyther S, Mooney M, et al: New response evaluation criteria in solid tumours: Revised RECIST guideline (version 1.1). J Eur J Cancer 45: 228-247, 2009.

17. U.S.Department of Health and Human Services, National Institutes of Health and National Cancer Institute: Common Terminology Criteria for Adverse Events (CTCAE). Version 4.0. https://evs.nci. nih.gov/ftp1/CTCAE/CTCAE_4.03/Archive/CTCAE_4.0_200905-29_QuickReference_8.5x11.pdf. Accessed May 28, 2009.

18. Lemma GL, Lee JW, Aisner SC, Langer CJ, Tester WJ, Johnson DH and Loehrer PJ Sr: Phase II study of carboplatin and paclitaxel in advanced thymoma and thymic carcinoma. J Clin Oncol 29: 2060-2065, 2011.

19. Makimoto G, Fujiwara K, Watanabe H, Kameyama N, Matsushita M, Rai K, Sato K, Yonei T, Sato T and Shibayama T: nab-paclitaxel in combination with carboplatin for a previously treated thymic carcinoma. Case Rep Oncol 7: 14-17, 2014

20. Igawa S, Yanagisawa N, Niwa H, Ishihara M, Hiyoshi Y, Otani S, Katono K, Sasaki J, Satoh Y and Masuda N: Successful chemotherapy with carboplatin and nab-paclitaxel for thymic large cell neuroendocrine carcinoma: A case report. Oncol Lett 10: 3519-3522, 2015.

21. Zhan P, Xie H and Yu LK: Response to nab-paclitaxel and nedaplatin in a heavily-metastatic thymic carcinoma: A case report. Oncol Lett 9: 1715-1718, 2015.

22. Shima H, Ozasa H, Tsuji T, Ajimizu H, Nomizo T, Yagi Y, Sakamori Y, Nagai H, Minamiguchi S, Kim YH and Mishima M Response to chemotherapy with carboplatin plus albumin-bound paclitaxel in a patient with lymphoepithelioma-like thymic carcinoma: A case report. Mol Clin Oncol 4: 715-718, 2016.
23. Funaishi K, Yamasaki M, Saito N, Daido W, Ishiyama S, Deguchi N, Taniwaki M and Ohashi N: First-line treatment with carboplatin plus nab-paclitaxel and maintenance monotherapy with nab-paclitaxel for a thymic carcinoma: A case report. Case Rep Oncol 10: 571-576, 2017.

24. Ley J, Wildes TM, Daly K, Oppelt P and Adkins D: Clinical benefit of nanoparticle albumin-bound-paclitaxel in recurrent/metastatic head and neck squamous cell carcinoma resistant to cremophor-based paclitaxel or docetaxel. Med Oncol 34: 28 , 2017.

25. Maurer K, Michener C, Mahdi H and Rose PG: Universal tolerance of nab-paclitaxel for gynecologic malignancies in patients with prior taxane hypersensitivity reactions. J Gynecol Oncol 28: e38, 2017.

26. Sato J, Satouchi M, Itoh S, Okuma Y, Niho S, Mizugaki H, Murakami H, Fujisaka Y, Kozuki T, Nakamura K, et al: Lenvatinib in patients with advanced or metastatic thymic carcinoma (REMORA): A multicentre, phase 2 trial. Lancet Oncol 21: 843-850, 2020

27. Gong W, Sun P, Mu Z, Liu J, Yu C and Liu A: Efficacy and safety of nab-paclitaxel as second-line chemotherapy for locally advanced and metastatic non-small cell lung cancer. Anticancer Res 37: 4687-4691, 2017.

28. Nakao A, Uchino J, Igata F, On R, Ikeda T, Yatsugi H, Hirano R, Sasaki T, Tanimura K, Imabayashi T, et al: Nab-paclitaxel maintenance therapy following carboplatin + nab-paclitaxel combination therapy in chemotherapy naive patients with advanced non-small cell lung cancer: Multicenter, open-label, single-arm phase II trial. Invest New Drugs 36: 903-910, 2018.

This work is licensed under a Creative Commons Attribution-NonCommercial-NoDerivatives 4.0 International (CC BY-NC-ND 4.0) License. 